\title{
AVALIAÇÃO DA CONDIÇÃO DE ÁRVORES URBANAS NOS PRINCIPAIS PARQUES E PRAÇAS DO MUNICÍPIO DE IRATI-PR.
}

Leonardo Serpa Schallenberger ${ }^{1}$, Antonio José de Araujo ${ }^{2}$, Michiko Nakai de Araujo ${ }^{3}$, L. Jay Deiner ${ }^{4}$, Gilmara de Oliveira Machado ${ }^{5}$.

(recebido em 22.10.2009 e aceito para publicação em 10.06.2010)

\section{RESUMO}

Este estudo teve como principal objetivo avaliar a condição das árvores urbanas do Parque Aquático de Exposição Agro-Industrial Santa Terezinha, Praça Etelvina Andrade Gomes, Edgar Andrade Gomes, Praça Infantil Dona Nóca, Colina Nossa Senhora das Graças e a Praça da Bandeira. As praças selecionadas são as mais freqüentadas pela população da cidade de Irati no estado do Paraná. A análise foi realizada mediante uma metodologia semi-qualitativa, a qual utiliza como parâmetros variáveis relacionadas à condição do tronco, taxa de crescimento recente, vitalidade da árvore, doenças pragas e parasitas, vigor da copa e longevidade remanescente. Essas variáveis são numericamente pontuadas e por meio de comparação com pontuações pré-estabelecidas e tabeladas é possível classificar cada árvore em excelente, boa, regular, ruim ou péssima. Dos seis locais de estudo, foram avaliadas 615 árvores de diferentes espécies. De acordo com os resultados, $19,35 \%$ das árvores foram classificadas em excelentes, 35,93\% em boas, 32,36\% em regulares, 11,06\% em ruins e $1,3 \%$ se enquadraram na condição péssima. Devido suas peculiaridades, cada local foi analisado também em particular, sendo abordadas as principais espécies constituintes e principais motivos causadores de efeitos negativos na condição geral das árvores. Observou-se, que na maioria dos casos, a condição geral dos indivíduos foram decorrentes da presença de erva-de-passarinho, espaçamentos inadequados entre árvores,

\footnotetext{
1. Acadêmico do Curso de Engenharia Florestal, Universidade Estadual do Centro Oeste (UNICENTRO), Irati - PR, leoserpas@hotmail.com

2. Engenheiro Florestal,PhD., Professor do Departamento de Engenharia Florestal, Universidade Estadual do Centro Oeste (UNICENTRO), Irati - PR, dearaujo@onda.com.br

${ }^{3}$.Engenheira Florestal, MSc., Professora do Departamento de Engenharia Florestal, Universidade Estadual do Centro Oeste (UNICENTRO), Irati - PR. michikodearaujo@onda.com.br

${ }^{4}$.Graduado em Química, PhD., Professor do Departamento de Química, City University of NY, New York, NY.deiner76@hotmail.com

5. Graduada em Ciências Exatas,PhD., Professora do Departamento de Engenharia Florestal, Universidade Estadual do Centro Oeste (UNICENTRO), Irati - PR,gilmaramachado@yahoo.com.br
}

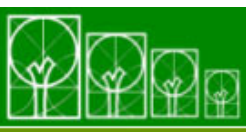

$\mathbf{S} \cdot \mathbf{B} \cdot \mathbf{A} \cdot \mathbf{U}$ Soc. Bras. de Arborização Urbana 
lesões resultantes de podas drásticas ou realizadas sem o uso de técnicas adequadas, bem como da necessidade de remoção e substituição de árvores em casos extremos.

Palavras-chave: arborização urbana, condição de árvores urbanas, parques e praças, cidade de Irati/Paraná.

\section{EVALUATION OF THE URBAN TREE CONDITION IN THE MAIN PARKS AND SQUARES IN IRATI, PARANÁ, BRAZIL}

\section{ABSTRACT}

The main goal of this research was to evaluate the condition of urban trees in the city of Irati (Paraná, Brazil). The trees were chosen from six locations comprising a representative sample of the city parks. They are also the most visited parks in the city. The chosen parks were: "Parque Aquático de Exposição Agro-Industrial Santa Terezinha", "Praça Etelvina Andrade Gomes", "Edgar Andrade Gomes", "Praça Infantil Dona Nóca", "Colina Nossa Senhora das Graças" and "Praça da Bandeira". The trees' conditions were rated using a semi-quantitative methodology based on evaluations of tree trunk condition, tree development, tree vitality, presence of plague attack, tree top characteristics and tree longevity. Each variable received a specific number based on comparison to a standard rubric. The variables were then summed to provide an overall tree classification: excellent, good, average, below average or poor. Among the 6 parks, 615 trees were evaluated from 37 different species. From the 615 trees evaluated, 19\% were classified as excellent, $36 \%$ as good, $32 \%$ as average, $11 \%$ as below average and only $1 \%$ as poor. Differences between parks were also evaluated. Finally, it was found that irrespective of the park or species, mistletoe disease and inadequate tree spacing were the main causes of poor tree conditions. In certain cases, poor tree pruning technique exacerbated crowded conditions.

Keywords: urban forest, tree condition in urban environments, parks and squares, Irati / Paraná. 


\section{INTRODUÇÃO}

A condição de uma árvore urbana pode ser avaliada por meio da sua saúde, vigor, vitalidade, taxa de crescimento, imperfeições físicas, infestações e expectativa de vida, expressando o estado em que a árvore se encontra e não a condição do local onde ela está se desenvolvendo. A avaliação da condição de árvores urbanas é de suma importância para o manejo da arborização de ruas e a gestão da floresta urbana como um todo. A necessidade de remoção de árvores, poda ou tratamentos fitossanitários pode ser detectada e quantificada ao avaliar-se a condição das árvores. Desta forma, a condição é um fator importante na metodologia de avaliação monetária de árvores que segue diversas variáveis, como o fator condição, agrupadas em uma equação matemática, e avaliação de árvores de risco que leva em consideração a condição da árvore e possíveis alvos do patrimônio público a privado que podem ser atingidos quando houver a queda da árvore ou de galhos (ARAUJO; ARAUJO, 2002, p.166).

Em 1931, a Associação de Parques Florestais de Michigan (MFPA) já demonstrava preocupações quanto a desenvolver metodologias eficientes para avaliar a condição de árvores urbanas, publicando as primeiras diretrizes, que a partir de 1956 foram revisadas e atualizadas. No ano de 1997 a MFPA passou a ser um capítulo da Sociedade Internacional de Arboricultura (ISA), realizando-se em 1982 uma revisão significativa, adequando o guia de avaliação da MFPA de acordo com as diretrizes da ISA. No Brasil, a primeira versão adaptada dessa metodologia foi apresentada no VII Encontro Nacional sobre Arborização Urbana em Belo Horizonte, MG (ARAUJO, 1997. p.69). Este método foi citado por Coltro e Miranda (2007), entretanto nenhum resultado foi apresentado utilizando esta metodologia, não tendo assim nenhum trabalho demonstrando os resultados da aplicação deste modelo no país.

Com a crescente busca de espaços verdes pela sociedade atual, a arborização de vias públicas, parques e praças vêm sendo uma grande alternativa para as cidades, pois as árvores urbanas quando bem implantadas e manejadas transmitem múltiplos benefícios e estão longe de serem caracterizadas como um problema. Os benefícios podem ser de ordem estética, relacionados principalmente a efeitos visuais que as plantas fornecem, proporcionando um contato do homem com a natureza, produzindo um efeito harmônico através de suas linhas suaves e orgânicas, formas, cores e texturas, criando paisagens específicas, proporcionando identidade às ruas. Quanto ao meio ambiente incluem benefícios na melhoria do microclima, amenização da poluição atmosférica e acústica, (1) (x)

S $\cdot \mathbf{B} \cdot \mathbf{A} \cdot \mathbf{U}$ Soc. Bras. de Arborização Urbana 
proteção do solo e fauna, diminuição da velocidade do vento e fornecendo sombra a população humana. Fontes benéficas de ordem física estão relacionadas ao conforto que as árvores proporcionam com a alteração do microclima, já as psíquicas trazem benefícios incalculáveis ao homem, principalmente na atenuação do estresse. A arborização urbana também é positiva no fomento ao turismo, incentivando atividades lúdicas e físicas o que pode propiciar uma diminuição do sedentarismo populacional e no desenvolvimento da educação ambiental, estando assim, relacionada a valores políticos, sociais e econômicos (BIONDI; ALTHAUS, 2005). Proporciona também maior absorção da radiação ultravioleta, dióxido de carbono e redução do impacto da água da chuva sobre o solo com diminuição de seu escoamento superficial pelo aumento da permeabilidade (MILANO; DALCIN, 2000). Contribui desta forma como fonte de recreação e lazer urbanos, estimulando a ampliação do círculo social (SOUZA, 1995).

Quanto ao seqüestro de carbono, estima-se que cada árvore em crescimento pode absorver até 180 quilos de gás carbônico da atmosfera por ano, principalmente as que têm o crescimento mais lento, pois a partir do plantio, a árvore já começa a realizar o seqüestro do $\mathrm{CO}_{2}$ da atmosfera, só diminuindo esta atividade na fase adulta (PREFEITURA MUNICIPAL DE MANAUS, 2008a).

Para produção de efeitos positivos as árvores devem ser submetidas a adequados tratos silviculturais, desde a produção de mudas de alta qualidade à manutenção com podas regulares em indivíduos adultos. No Brasil, o que ocorre na maioria das vezes, salvo raras exceções, é que a arborização urbana não passa por um planejamento prévio, sendo em sua maioria executada com improvisos de técnicos não especializados na área, não havendo existência de políticas dirigidas ao setor, assim como conscientização da população de sua importância (SANTOS, 2001).

Contudo essa mentalidade está aos poucos se modificando, a notar pelos eventos da área como o Congresso Nacional de Arborização Urbana organizado pela Sociedade Brasileira de Arborização Urbana (SBAU). Resta então, a correção dos erros já constatados (escolha inadequada de espécies, plantio em locais inadequados, podas mal feitas, etc) e a potencialização das ações notoriamente bem sucedidas, como em Porto Alegre - RS que possui um completo plano de manejo de arborização de vias públicas, Maringá - PR que é considerada uma das cidades mais arborizadas do país, Curitiba - PR que dispõe de grande tecnologia, experiência e profissionais habilitados, obtendo ótimos resultados, e outras cidades como Vitória - ES, Recife - PE, Manaus - AM. Para tal, um inventário de análise da condição é fundamental, permitindo conhecer a situação de cada município, quais atitudes devem ter continuidade e que valores devem ser repensados. (SANTOS; TEIXEIRA, 2001). 
Quando a arborização é realizada sem um bom planejamento, observam-se problemas como a destruição de calçadas pelo excessivo afloramento de raízes devido à impermeabilização do solo decorrente da presença de pavimentação, disseminação de pólen alergênico na população, queda de galhos deficientes de poda, infestações por doenças e pragas como a erva-de-passarinho, gerando perdas de valores estéticos, danos a rede de fiação elétrica, dentre outros. (ARAUJO; ARAUJO, 2002, p.166).

Todavia, com o recente crescimento da arboricultura no Brasil, gestores municipais tem voltado suas atenções quanto à qualidade das árvores que ocupam os espaços urbanos na busca da otimização de suas diversas funções. Desta maneira, há pesquisadores que demonstram um forte interesse no estudo de metodologias que permitem avaliar em que condições se encontram as florestas urbanas, buscando a elaboração de projetos administrativos mais eficientes. Biondi e Reissmann (1997) realizaram estudos relacionados, avaliando o vigor das espécies Acer negundo L. e Tabebuia chrysotricha (Mart ex DC.) Standl., seguindo parâmetros quantitativos de avaliação, como: diâmetro de copa, perímetro à altura do peito, peso de folhas, elongação do ramo, peso do ramo e área foliar. Gonçalves et al. (2007) preocupou-se com a criterização para análise de parâmetros que possam determinar a supressão de determinado indivíduo arbóreo, analisando diversas variáveis como a paisagística verificando a raridade da espécie no ambiente estudado; a afetividade, que diz respeito ao valor de estima da população pelo indivíduo arbóreo e o posicionamento em relação ao contexto urbano; a ecológica, que se refere à natividade da espécie, idade e importância ecológica do indivíduo no local; fitossanitária, presença de doenças, ocorrência de pragas, outros problemas como madeira frágil e riscos avaliados pelos conflitos aéreos, subterrâneos e iminência de queda.

Devido à grande subjetividade das metodologias anteriores, Loboda et al. (2005) com a finalidade de avaliar áreas verdes em espaços públicos, ao fazer a avaliação específica de árvores, aplicou a metodologia desenvolvida por Milano (1988) a qual tem um perfil mais objetivo, onde se atribui notas aos indivíduos de 1 a 3 , sendo considerado 1 como árvore boa (vigorosa, que não apresenta sinais de danos mecânicos), 2 como árvore satisfatória (apresenta condição e vigor médios para o local, pode apresentar pequenos problemas de danos físicos) e 3 como ruim (apresenta estado geral de declínio e pode apresentar severos danos físicos).

Levando em consideração as informações acima apresentadas, o presente estudo teve como principal objetivo identificar e avaliar a condição das árvores urbanas de seis parques localizados em Irati, Paraná. Realizou-se o levantamento das espécies constituintes 
do componente arbóreo para cada parque e utilizando parâmetros relacionados à condição do tronco, taxa de crescimento recente, vitalidade da árvore, doenças pragas e parasitas, vigor da copa e longevidade remanescente foi possível classificar cada árvore em excelente, boa, regular, ruim ou péssima por meio de comparação com pontuações pré-estabelecidas e tabeladas. Devido suas peculiaridades, cada parque foi analisado também em particular sendo pesquisado os principais motivos causadores de efeitos negativos na condição geral das árvores.

\section{MATERIAS E MÉTODOS}

O município de Irati está situado a $25^{\circ} 27^{\prime}$ '56" de latitude Sul com interseção com o meridiano 50 $37^{\prime}$ '51" de longitude Oeste, no estado do Paraná, com altitude de aproximadamente 812 metros. Localizado a $138 \mathrm{~km}$ da capital Curitiba, inserido na zona fisiográfica de IRATI, na sub-região dos pinhais no Segundo Planalto. O clima é do tipo temperado úmido com verão temperado $(\mathrm{Cfb})$ de acordo com a classificação climática de Köppen, com freqüentes ocorrências de geadas no período de inverno. As temperaturas médias anuais são de $24,2^{\circ} \mathrm{C}$ na estação quente e de $11,0^{\circ} \mathrm{C}$ na estação fria. A média mensal de precipitação pluviométrica é de 193,97mm com umidade relativa do ar mensal média de $79,58 \%$. Na base mineral encontra-se siltito, basalto e arenito, com predominância dos solos sílticos argilosos (afloramentos rochosos), litólicos, coluviais e saprolíticos (PREFEITURA MUNICIAL DE IRATI - PR, 2008).

O estudo foi realizado em seis principais parques e praças da cidade, sendo que o critério para definir as áreas como principais baseou-se na observação do maior uso como para lazer, esportes e recreação ao ar livre exercidos pela população. Desta forma, foram selecionados o Parque Aquático de Exposição Agro-Industrial Santa Terezinha (A), Praça Etelvina Andrade Gomes (B), Edgar Andrade Gomes (C), Praça Infantil Dona Nóca (D), Colina Nossa Senhora das Graças (E) e a Praça da Bandeira (F).

O Parque Aquático de Exposição Agro-Industrial Santa Terezinha (A) esta localizado aos 2528'13"S e 50³9'51"O, no bairro Rio Bonito, tem em seu entorno as ruas Caetano Zaperllon, Expedicionário José de Lima, Adão Panka, e Lino Esculápio.

A Praça Etelvina Andrade Gomes (B) está localizada em frente à Igreja Matriz Nossa Senhora da Luz, estando compreendida entre o cruzamento das ruas Coronel Pires, Alfredo Kaminski e Alfredo Bufrem, com coordenadas geográficas aproximadas de 2528'11"S e $50^{\circ} 38^{\prime} 45^{\prime \prime} \mathrm{O}$.

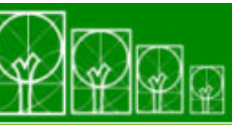

$\mathbf{S} \cdot \mathbf{B} \cdot \mathbf{A} \cdot \mathbf{U}$ Soc. Bras. de Arborização Urbana 
Aos 2526'55"S e 5038'10"O está a Praça Edgar Andrade Gomes (C), tendo em seu entorno as ruas Edgar Távora, Benjamim Constant, e Alameda Virgílio Moreira.

A Praça Infantil Dona Nóca (D) está situada em frente ao Cemitério Municipal, no cruzamento das ruas Dezenove de Dezembro, Coronel Gracia e Barão do Rio Branco, com coordenadas de 25 $28^{\prime} 03^{\prime \prime}$ e e 5039'04"O.

A Colina Nossa Senhora das Graças (E) encontra-se na intersecção da Rua João Maria dos Santos com a Travessa Irmã Michelina, aos aproximados 2527'38”S e $50 \div 38$ '38”'O.

A Praça da Bandeira $(F)$ esta inserida em frente ao início das instalações da estação ferroviária, circundada pelas ruas Carlos Thoms, Marechal Deodoro, Conselheiro Zacarias Castelinho com latitudes de 2527'55"S e 503'38”O.

Foram somente avaliados indivíduos arbóreos, desconsiderando-se as árvores mortas, muito jovens com altura inferior a 1,8 metros de altura, e aqueles que devido a adversidades do meio em que se encontravam comprometiam a análise visual, como, por exemplo, árvores caducifólias que se apresentavam totalmente sem folhas e com inexpressivo surgimento de gemas apicais, dificultando assim a análise de fatores como Vitalidade da Árvore (VA) e Vigor da Copa (VC), que representam uma pequena porcentagem da amostra. Para a obtenção de resultados mais apurados no momento da análise foi feita à comparação entre indivíduos de maior e menor vigor aparente da mesma espécie localizados próximos uns aos outros.

A metodologia utilizada para avaliação foi desenvolvida pela Associação de Parques Florestais de Michigan (MFPA) e adaptada por ARAUJO (1997). As variáveis analisadas foram Condição do tronco (CT), Taxa de Crescimento Recente (TC), Vitalidade da Árvore (VA), Doenças, Pragas e Parasitas (DP), Vigor da Copa (VC), e Longevidade Remanescente (LR). Cada variável gera um valor numérico e a soma de todos os valores obtidos expressa a condição da árvore, sendo que de 24 a 22 representa uma árvore de condição excelente, de 21 a 18 é boa, de 17 a 13 regular, de 12 a 9 ruim e de 8 a 6 péssima.

No que tange a Condição do Tronco (CT), o tronco da árvore é examinado quanto a sua integridade e imperfeições físicas bem como o apodrecimento e presença de ocos extensivos ou seções de casca faltando. A nota pode variar de 1 a 5 . A nota máxima (5) é atribuída a um tronco sólido e sadio. Uma nota intermediária (3) é aferida quando houver seções de casca faltando e a nota mínima (1) é dada quando existirem apodrecimentos e ocos extensivos. Danos físicos causados à casca decorrentes de podas mal executadas (1) POP

$\mathbf{S} \cdot \mathbf{B} \cdot \mathbf{A} \cdot \mathbf{U}$ Soc. Bras. de Arborização Urbana 
serão considerados. Ataques de insetos, doenças ou parasitas existentes sobre o tronco, entretanto, não devem ser considerados neste fator, mesmo que exsudações e outros sinais sejam evidentes (ARAUJO; ARAUJO, 2002, p.166).

A Taxa de Crescimento Recente (TC) se refere aos lançamentos ou segmentos de crescimento observáveis na extremidade dos ramos ou galhos. Esse crescimento é variável entre espécies. A experiência do avaliador é muito importante e vai sendo adquirida e consolidada á medida que aumenta o número de avaliações realizadas. Na maioria das espécies, os lançamentos podem ser identificados pelas cicatrizes da gema dormente que antecede a cada novo lançamento na estação de crescimento. A nota máxima pode variar de (3) para um crescimento em torno da média ou acima para a espécie, (2) para uma taxa de crescimento abaixo da média para a espécie, até a nota mínima (1) para um crescimento insignificante (ARAUJO; ARAUJO, 2002, p.166).

A Vitalidade da Árvore (VA) foi avaliada em relação à ocorrência de sinais de morte progressiva (dieback). Dieback é a morte progressiva de brotos e ramos, partindo da ponta (extremidade) do ramo, em direção à sua base. Pode ser causada por muitos fatores, como fungos, bactérias, temperaturas baixas, seca, drenagem e aeração deficientes, bem como toxidez química e ataque de insetos. A nota pode variar de 1 a 5 . A nota máxima (5) é atribuída quando não existirem sinais de morte progressiva. Uma nota intermediária (3) pode ser atribuída quando forem observados sinais de morte progressiva em estádio intermediário e a nota mínima (1) é atribuída quando dois ou mais ramos principais estiverem mortos, com morte progressiva em estádio avançado (ARAUJO; ARAUJO, 2002, p.166).

A nota de Doenças Pragas e Parasitas (DP) varia de 1 a 3 . A nota máxima (3) é atribuída quando a árvore estiver sem infestações ou injúrias desfigurantes presentes. $A$ nota 2 atribui-se quando a árvore estiver com infestações crônicas ou desfigurante. Já a nota mínima (1) é atribuída quando a árvore estiver com infestação avançada, usualmente fatal. A ocorrência de erva-de-passarinho deve ser considerada neste fator. É importante mencionar que a existência de epífitas (vegetais que vivem sobre outros sem retirar nutrientes, apenas apoiando-se neles) sobre a árvore não deve ser confundida com a infestação de hemiparasitas como é o caso da erva-de-passarinho. Doenças e pragas sobre o tronco ou copa devem ser considerados neste fator. (ARAUJO; ARAUJO, 2002, p.166).

O vigor da Copa (VC) é avaliado pelo tamanho e cor das folhas. Em árvores sem folhas devido à estação do ano, a avaliação pode ser feita pelas gemas presentes nos ramos da árvore. As gemas ou brotos são os tecidos que originam as brotações ou flores. $A$ avaliação e gemas ou brotos exige um treinamento e familiaridade com as características da espécie em observação. Na maioria das vezes o vigor da copa pode ser avaliado pelas 
folhas. A nota pode variar de 1 a 5 . A nota máxima (5) é atribuída quando as folhas são de tamanho e cor normais. Uma nota intermediária (3) pode ser atribuída quando as folhas forem de tamanho reduzido ou um pouco descoloridas e a nota mínima (1) quando as folhas forem pequenas, cloróticas, apresentando severos sinais de queima ou de cor outonal antecipada. Quando a avaliação basear-se nas gemas ou brotos, atribui-se a nota máxima quando as gemas forem de tamanho normal e túrgida. A nota intermediária (3) pode ser atribuída quando as gemas forem de tamanho reduzido e a nota mínima (1) quando forem observadas gemas pequenas e mortas (ARAUJO; ARAUJO, 2002, p.166).

A longevidade remanescente (LR) refere-se á estimativa de quantos anos a árvore poderá ainda viver. A longevidade natural é variável entre espécies e é importante conhecerse essa informação. A avaliação da longevidade remanescente, entretanto, deve caracterizar a expectativa da vida para o indivíduo em análise. A nota pode variar de 1 a 3 . A nota máxima (3) é atribuída quando se estima que a árvore possa viver acima de 20 anos. Uma nota intermediária (2) é atribuída quando estima-se uma expectativa de vida entre 5 e 20 anos e a nota mínima (1) quando essa expectativa é menor do que 5 anos (ARAUJO; ARAUJO, 2002, p.166).

Devem-se seguir os critérios pré-estabelecidos de pontuação definida com clareza, e definir de maneira objetiva e padronizada as características em avaliação, assim como o treinamento do avaliador, sua experiência na área e o conhecimento das espécies focadas são fundamentais para diminuir erros de avaliação.

O estudo foi realizado de 01/09/08 a 28/09/08 no período de transição entre o inverno e a primavera. Elaborou-se uma ficha de campo contendo informação sobre o local, data, no da árvore, espécie, CT, TC, VA, DP, VC, LR, Total (somatório das variáveis) e condição.

\section{RESULTADOS E DISCUSSÂO}

$\mathrm{Na}$ análise feita no parque Aquático de Exposição Agro-Industrial Santa Terezinha (A) e nas praças Etelvina Andrade Gomes (B), Edgar Andrade Gomes (C), Praça Infantil Dona Nóca (D), Colina Nossa Senhora das Graças (E) e Praça da Bandeira (F), foram avaliadas 615 árvores de 37 diferentes espécies de 24 famílias botânicas (Tabela 1). Todas as praças se localizam na área urbana de Irati. Constatou-se que das árvores avaliadas as predominantes foram Syagrus romanzoffiana Cham. (22,44\%), Ligustrum lucidum W. T. Aiton $(9,59 \%)$ que se mostrou presente em todos os ambientes avaliados, Platanus (1) (P) 
acerifolia (Ainton) Willd. (7,80\%), Tipuana tipu (Benth.) O. Kuntz (6,67\%), Lagerstroemia indica L. (5,53\%), Salix babylonica L. (5,53\%), Cryptomeria japonica Thunberg. (4,55\%) e Araucaria angustifolia (Bert.) O Kuntze (3,25\%).

TABELA 1- Espécies e Famílias botânicas das árvores avaliadas.

\begin{tabular}{|c|c|c|c|}
\hline ESPÉCIE & Família & № Indivíduos & Ocorrência \\
\hline Acer Negundo L. & Sapindaceae & 6 & A \\
\hline $\begin{array}{c}\text { Araucaria angustifolia (Bert.) O } \\
\text { Kuntze. }\end{array}$ & Araucariaceae & 20 & $\mathrm{~B}, \mathrm{~F}$ \\
\hline Bauhinia forficata Link. & $\begin{array}{l}\text { Fabaceae - } \\
\text { Cercideae }\end{array}$ & 5 & B \\
\hline Caesalpinia ferrea Mart. & $\begin{array}{c}\text { Fabaceae - } \\
\text { Caesalpinioideae }\end{array}$ & 5 & $\mathrm{~B}$ \\
\hline Camellia japonica L. & Theaceae & 3 & C \\
\hline $\begin{array}{c}\text { Chamaecyparis pisifera Siebold \& } \\
\text { Zucc. }\end{array}$ & Cupressaceae & 14 & A \\
\hline Cordyline dracaenoides Kunth. & Dracaenaceae & 2 & $\mathrm{~B}$ \\
\hline Cryptomeria japonica Thunberg. & Taxodiaceae & 28 & $A, B$ \\
\hline Cupressus Iusitanica Miller. & Cupressaceae & 20 & $A, B$ \\
\hline $\begin{array}{c}\text { Cupressus macrocarpa Hartw. Ex } \\
\text { Gordon. }\end{array}$ & Cupressaceae & 13 & $A, E$ \\
\hline Eriobotrya japonica (Thunb.) Lindl. & Rosaceae & 4 & $A, F$ \\
\hline Eugenia uniflora L. & Myrtaceae & 4 & A \\
\hline Grevillea robusta A. Cunn. Ex R. Br. & Proteaceae & 17 & $A, B, C, D$ \\
\hline Jacaranda mimosifolia D. Don. & Bignoniaceae & 10 & $\mathrm{~A}, \mathrm{~B}, \mathrm{C}$ \\
\hline Juniperus chinensis L. & Cupressaceae & 17 & $C, E$ \\
\hline Lagerstroemia indica L. & Lythraceae & 34 & $A, B, C, E$ \\
\hline Ligustrum lucidum W. T. Aiton. & Oleaceae & 59 & $A, B, C, D, E, F$ \\
\hline $\begin{array}{c}\text { Livistona chinensis (Jack.) R. Br. } \\
\text { ex. Mart. }\end{array}$ & Arecaceae & 9 & $\mathrm{C}, \mathrm{B}$ \\
\hline Magnolia grandiflora L. & Magnoliacea & 5 & $A, B$ \\
\hline Melia azedarach L. & Meliaceae & 10 & $A, C$ \\
\hline Mimosa scrabella Benth. P. & $\begin{array}{l}\text { Fabaceae - } \\
\text { Mimosoideae }\end{array}$ & 2 & $A, E$ \\
\hline Nerium oleander L. & Apocynaceae & 3 & $\mathrm{C}, \mathrm{B}$ \\
\hline $\begin{array}{l}\text { Parapiptadenia rigida (Bentham) } \\
\text { Brenan. }\end{array}$ & $\begin{array}{l}\text { Fabaceae - } \\
\text { Mimosoideae }\end{array}$ & 7 & A \\
\hline $\begin{array}{c}\text { Chamaecyparis obtusa Siebold \& } \\
\text { Zucc. }\end{array}$ & Cupressaceae & 6 & C \\
\hline Pinus sp. & Pinaceae & 1 & $\mathrm{C}$ \\
\hline Platanus acerifolia (Ainton) Willd. & Platanaceae & 48 & A \\
\hline Psidium cattleianum Sabine. & Myrtaceae & 7 & $A$ \\
\hline Salix babylonica L. & Salicaceae & 34 & A \\
\hline Schinus molle L. & Anacardiaceae & 3 & $\mathrm{~F}$ \\
\hline Schinus terebinthifolius Raddi. & Anacardiaceae & 2 & $E$ \\
\hline
\end{tabular}




\begin{tabular}{|c|c|c|c|}
$\begin{array}{c}\text { Schizolobium parahyba (Vell.) S. F. } \\
\text { Blake. }\end{array}$ & $\begin{array}{c}\text { Fabaceae - } \\
\text { Caesalpinoideae }\end{array}$ & 1 & B \\
\hline Senna multijuga Rich. I. \& B. & $\begin{array}{c}\text { Fabaceae - } \\
\text { Caesalpinoideae }\end{array}$ & 12 & B \\
\hline Syagrus romanzoffiana Cham. & Arecaceae & 138 & A, B, C, D \\
\hline Tabebuia alba (Cham.) Sandw. & Bignoniaceae & 12 & B, C, F \\
\hline Tabebuia heptaphylla (Vell.) & Bignoniaceae & 11 & A, B \\
\hline Terminalia catappa L. & Combretaceae & 2 & A, B \\
\hline Tipuana tipu (Benth.) O Kuntz. & $\begin{array}{c}\text { Fabaceae - } \\
\text { Caesalpinoideae }\end{array}$ & 41 & A, B, C \\
\hline TOTAL & - & 615 & - \\
\hline
\end{tabular}

A metodologia utilizada, na obtenção de resultados indicadores da qualidade das espécies arbóreas, se mostrou bastante eficiente e de fácil aplicação. A grande maioria das árvores possui características as quais possibilitam sua classificação direta em uma das categorias intituladas como excelente, boa, regular, ruim e péssima, estando inclusive em conformidade com o sentido literal das palavras classificatórias. Porém, as espécies de palmeiras Livistona chinensis (Jack.) R. Br. ex. Mart. e Syagrus romanzoffiana Cham. da família Arecaceae apresentaram maior dificuldade na avaliação dos parâmetros condição do tronco (CT) e taxa de crescimento recente (TC). Observou-se também um aumento significativo na experiência do avaliador no que tange a utilização da metodologia de pesquisa ao longo do exercício freqüente de coleta de dados tornando-o apto a classificar árvores de forma precisa gradativamente em tempos menores, estando em conformidade com Araujo (2002).

No que tange a avaliação geral da condição das árvores dos parques e praças de Irati-Pr, Tabela 2, foi observado que, em média, 119 indivíduos (19,35\% do total) foram avaliados em excelentes. A condição boa foi a mais expressiva, contando com 221 indivíduos (35,93\%). Na condição de excelentes e boas se encontram 55,28\% das árvores, não requerendo ou não necessitando emergencialmente de interferências visando melhorias. Árvores avaliadas na condição regular somaram 199 (32,36\%), com necessidades de tratos culturais como poda, controle de pragas e doenças, desbastes entre indivíduos próximos para minimizar efeitos de competição. Árvores na condição de ruins totalizaram 68 indivíduos $(11,06 \%)$ e péssimas 8 (1,30\%). As árvores ruins e péssimas $(12,36 \%)$ demonstraram atenção imediata, por serem indivíduos que podem ser árvores que representam risco tanto á vida de pessoas como ao patrimônio, necessitando serem

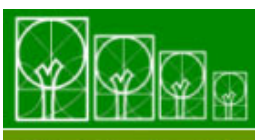

S $\cdot \mathbf{B} \cdot \mathbf{A} \cdot \mathbf{U}$ Soc. Bras. de Arborização Urbana 
substituídas para que o conjunto de árvores tenha suas funções ativas e potencializadas (Tabela 2).

TABELA 2 - Condição geral das árvores dos parques e praças de Irati - PR.

\begin{tabular}{|c|c|c|}
\hline CONDIÇÃO & No ÁRVORES & $\%$ \\
\hline Excelente & 119 & 19,35 \\
\hline Boa & 221 & 35,93 \\
\hline Regular & 199 & 32,36 \\
\hline Ruim & 68 & 11,06 \\
\hline Péssima & 8 & 1,30 \\
\hline
\end{tabular}

No que se refere à forma como foi realizada a arborização, com exceção de A, não houve um eficiente manejo, a notar pela necessidade de remoção de plantas em estágio terminal ou com ocos extensivos no caule, podas de manutenção e podas realizadas de maneira inadequadas, como se observa em B, D, E e F, favorecendo o ataque de fungos e insetos, estando de acordo com dados obtidos por Coltro e Miranda (2007), que citam a negligência quanto a podas e remoção de indivíduos mortos, causando algum dano, interferência e até mesmo risco a população Iratiense. É importante relatar que as podas têm função de adaptar a árvore e seu desenvolvimento ao espaço que ela ocupa. $O$ conhecimento das espécies mais utilizadas na arborização urbana, das técnicas apropriadas de podas e das ferramentas corretas para a execução das podas, permite que esta prática seja feita de forma a não danificar a árvore. Algumas podas são necessárias, como a poda de formação da muda e as podas de limpeza, que retiram galhos doentes, mortos, quebrados e mal formados. No caso de plantios inadequados, são feitas podas para correção de problemas gerados em função do plantio inconveniente, realizando-se podas de adequação e rebaixamento, com o cuidado de manter o formato original da árvore. A poda de segurança é aplicada quando as podas anteriores foram executadas incorretamente, ou quando alterações do ambiente urbano incompatibilizam a copa das árvores com seu meio. A finalidade desta poda é prevenir acidentes iminentes. Todavia, a poda é considerada uma agressão a árvore, já que partes do vegetal, como galhos, são removidos. Sendo assim, a poda deve ser feita de modo a facilitar a cicatrização do corte, caso contrário, a exposição do lenho fica susceptível ao ataque de fungos, insetos e bactérias responsáveis pelo apodrecimento de galhos e troncos (PREFEITURA MUNICIPAL DE MANAUS, 2008b). Segundo o Departamento de Parques e Áreas Verdes de São Paulo (DEPAVE), a poda é uma cirurgia e como toda cirurgia, deve ser evitada (PIVETTA; FERREIRA,1988). No que se refere à remoção de árvores, devem ser analisados os seguintes critérios: risco de queda, estado fitossanitário precário sem condições de recuperação, no caso de obras com 
interesse social confirmado e em casos de incompatibilidade da espécie com o espaço disponível (PREFEITURA MUNICIPAL DE PORTO ALEGRE, 2002).

O plantio de indivíduos muito próximos uns aos outros $(B, D$ e $E)$, resulta em grande competição por radiação solar, água e nutrientes, diminuindo o vigor das plantas, e conseqüentemente a sua condição. O espaçamento ideal varia de acordo com o porte da espécie, comumente recomenda-se o diâmetro da copa da espécie mais 1 metro, ou quando se deseja uma sombra contínua é igual ao diâmetro da copa da árvore no seu máximo desenvolvimento (PREFEITURA MUNICIPAL DE PORTO ALEGRE, 2002). Miller (1988) sugere espaçamentos de 7 metros entre árvores de pequeno porte, 10 metros entre árvores médias e 15 metros entre árvores de grande porte. Outro aspecto negativo identificado foi a ocorrência de infestação de pragas como a erva-de-passarinho encontradas em alguns locais em estágio avançado (B), desfigurando e suprimindo os hospedeiros. As ervas-depassarinho pertencem a um grupo de hemiparasitas composto pelas famílias Loranthaceae, Viscaceae, Misodendraceae, Eremolepidaceae e Santalaceae (AUKEMA, 2003), sendo duas destas, Viscaceae e Loranthaceae de importância mundial (TAINTER, 2002), encontradas em uma ampla faixa de ecossistemas, incluindo florestas boreais, tropicais úmidas e secas (NORTON; CARPENTER, 1998). A família Loranthaceae é a maior e contém pelo menos nove gêneros, muitos dos quais são abundantes nos trópicos, atacando grande variedade de hospedeiros (HARRIS, 1992). Ervas-de-passarinho podem ser removidas por meio do corte dos galhos infestados e queimados ou enterradas, pois possuem elevado poder de disseminação e podem comprometer a floresta urbana (ROTTA, 2001), como na cidade de Curitiba - Pr, que possui cerca de 300 mil árvores plantadas na área urbana, das quais 30\% apresentam incidência da erva (ZILIOTTO, et al., 1999).

Devido ao fato dos diferentes locais de estudo terem características muito próprias, levou-se em consideração também cada local de avaliação em particular já que os resultados de condição geral diferem significativamente entre si de uma praça para outra, tanto pelas espécies predominantes como pelas condições do meio em que estão inseridas. Os resultados da condição de cada praça e parque em particular são apresentados nas figuras 1,2 e 3 , onde as praças com características próximas foram expostas na mesma figura. 


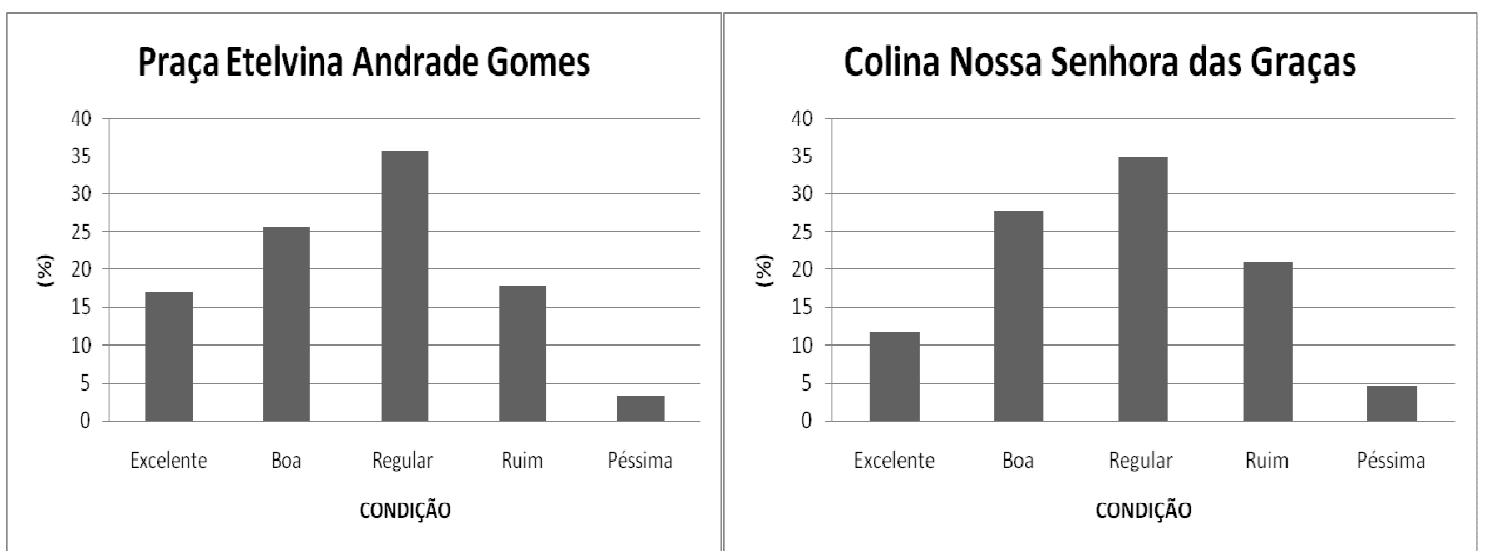

FIGURA 1- Condição das árvores, da Praça Etelvina Andrade Gomes (B) e Colina Nossa Senhora das Graças (E), em porcentagem.

A Praça Etelvina Andrade Gomes e a Colina Nossa Senhora das Graças apresentaram similar distribuição gráfica das condições das árvores, tendendo a forma piramidal (Figura 1). A condição regular prevaleceu nestes locais, seguida das condições boa e ruim, com menor ocorrência de árvores excelentes e péssimas. Em ambos locais haviam árvores muito agrupadas havendo competição direta pela energia radiante, gerando estresse nos indivíduos, pouco desenvolvimento e conseqüentemente prejuízos na condição destas árvores. A praça (B) foi recentemente reformada pela prefeitura e muitos indivíduos em condições precárias foram removidos, entretanto, houve relevante incidência de árvores infestadas por erva-de-passarinho (46,8\%), principalmente nas espécies Ligustrum lucidum W. T. Aiton., Grevillea robusta A. Cunn. ex R. Br. e Tipuana tipu (Benth.) O Kuntz. sendo que $20 \%$ das infestadas por pragas se encontravam em estágio crítico. Nesta área houve expressiva incidência de árvores velhas submetidas a podas feitas sem amparo técnico adequado comprometendo diretamente a sanidade dos indivíduos. As principais espécies presentes na avaliação foram Tipuana tipu (Benth.) O Kuntz (20), Senna multijuga Rich. I. \& B. (10) e Cryptomeria japonica Thunberg. (13). Na praça (E), encontravam-se muitas árvores agrupadas em fragmentos pequenos, com alta competição. As espécies mais comuns na praça foram Juniperus chinensis L. (17), Chamaecyparis pisifera Siebold \& Zucc (7) e Ligustrum lucidum W. T. Aiton. (6). 


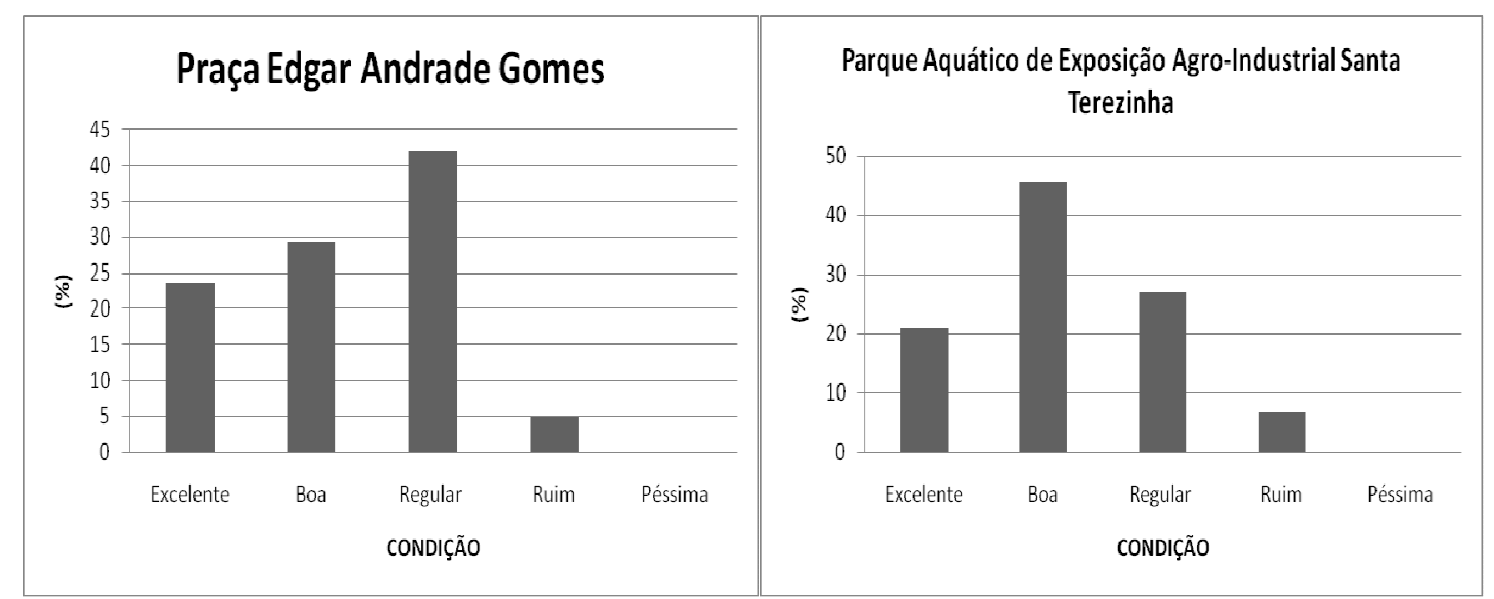

FIGURA 2 - Condição das árvores da Praça Edgar Andrade Gomes (C) e Parque Aquático de Exposição Agro-Industrial Santa Terezinha (A), em porcentagem.

A Praça Edgar Andrade Gomes (C) e o Parque Aquático de Exposição AgroIndustrial Santa Terezinha (A) apresentaram pequenos índices de árvores ruins e nenhuma árvore na condição péssima, tendo maior ocorrência de árvores boas e regulares. Quando comparadas com os outros locais do estudo, estas praças apresentam a maior porcentagem de árvores excelentes, $23,5 \%$ e 20,7\% respectivamente. Em ambos os locais as árvores se encontravam bem espaçadas umas das outras, com mínima competição por água, nutrientes e radiação solar. Não foram localizados indícios de ocorrência de pragas e doenças. Na praça (C) As espécies de maior ocorrência foram Syagrus romanzoffiana Cham. (24), Ligustrum lucidum W. T. Aiton. (20) e Lagerstroemia indica L. (16). O parque (C) foi o local de maior área e com maior número de árvores avaliadas (308). As espécie de maior ocorrência foram Syagrus romanzoffiana Cham. (107), Platanus acerifolia (Ainton) Willd. (48) e Salix babilonica (34). Todos os indivíduos da espécie Platanus acerifolia (Ainton) Willd. foram avaliados em excelentes ou bons, demonstrando ser uma espécie indicada para arborização de parques e praças onde os tratos silviculturais são poucos e limitados. 


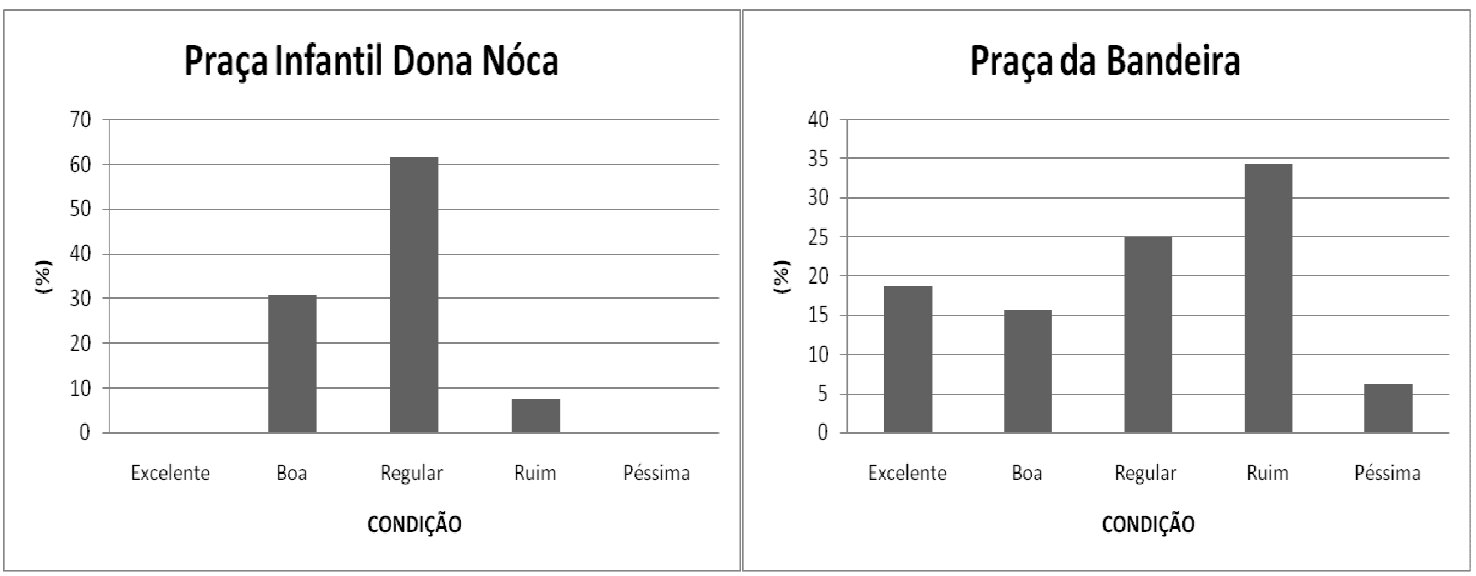

FIGURA 3 - Condição das árvores da Praça Infantil Dona Nóca (D) e Praça da Bandeira (F), em porcentagem.

A Praça Infantil Dona Nóca como a Praça da Bandeira, possuem as menores áreas dentre as estudadas. A praça (D) possui ao todo 13 árvores de três diferentes espécies, Ligustrum lucidum W. T. Aiton. (7), Grevillea robusta A. Cunn. ex R. Br. (4) e Syagrus romanzoffiana Cham. (2), todas com idade avançada e com relevante competição entre si em função de espaçamentos não proporcionais aos portes das árvores. Na avaliação não foram constatados indivíduos de condição excelente e péssima. A praça $(F)$ possui 32 árvores, com o predomínio da espécie Ligustrum lucidum W. T. Aiton. As árvores em sua maioria sofreram podas drásticas ao longo do tempo apresentando caules comprometidos, entretanto, necessitam de podas de manutenção adequadas.

\section{CONCLUSÕES}

Por meio da análise dos resultados obtidos nesse estudo pode-se concluir que a metodologia utilizada é prática e eficiente para avaliar a condição de árvores urbanas. Verificou-se a existência de uma considerável diversidade florística de espécies arbóreas entre as quais as de maior predominância nos parques e praças de Irati foram Syagrus romanzoffiana Cham., Ligustrum lucidum W. T. Aiton., Platanus acerifolia (Ainton) Willd. e Tipuana tipu (Benth.) O Kuntz.

No que tange a avaliação geral da condição das árvores, em média, 19,35\% do total foram avaliadas como excelente sendo a condição boa mais expressiva, contando com $35,93 \%$ das árvores. Árvores avaliadas na condição regular somaram 32,36\%, com necessidades de tratos culturais como poda, controle de pragas e doenças, desbastes entre indivíduos próximos para minimizar efeitos de competição. Árvores na condição de ruins 
totalizaram $11,06 \%$ e péssimas $1,30 \%$. As árvores ruins e péssimas, 12,36\%, precisam de atenção imediata, por serem indivíduos que representam risco tanto à vida de pessoas como ao patrimônio público, necessitando serem substituídas para que o conjunto de árvores tenha suas funções ativadas e potencializadas.

A Praça Edgar Andrade Gomes e o Parque Aquático de Exposição Agro-Industrial Santa Terezinha apresentaram pequenos índices de árvores ruins e nenhuma árvore na condição péssima, tendo maior ocorrência de árvores boas e regulares. Quando comparadas com os outros locais do estudo, estas praças apresentam a maior porcentagem de árvores excelentes, 23,5\% e 20,7\% respectivamente. A condição regular, aproximadamente 35\%, prevaleceu na Praça Etelvina Andrade Gomes e a Colina Nossa Senhora das Graças. Não foram constatados indivíduos de condição excelente e péssima na Praça Infantil Dona Nóca como na Praça da Bandeira, observando-se árvores com idade avançada e com relevante competição entre si em função de espaçamentos não proporcionais aos portes das árvores. As árvores em sua maioria sofreram podas drásticas ao longo do tempo apresentando caules comprometidos.

Verificou-se que o município não possui um plano de manejo da arborização urbana, a notar pelas deficiências de podas e pelas podas drásticas e outras realizadas sem amparo técnico adequado, bem como, necessidades de remoção de árvores velhas e suprimidas que oferece risco de queda a população e ao patrimônio. Verificou-se também infestação em estágio avançado de hemiparasitas como erva-de-passarinho e plantio de árvores em espaçamentos pequenos que resultam em grande competição entre indivíduos vizinhos.

Desta maneira, nota-se a importância do município de Irati possuir um planejamento da arborização urbana, para que seus parques e praças possam atender aos mais diversos objetivos da população, sem oferecer riscos e provocar danos ao patrimônio público. $O$ planejamento consiste em se revitalizar a arborização da cidade e traçar objetivos e metas a serem atingidas. O primeiro passo é fazendo um inventário das árvores da forma como foi realizado neste estudo, onde a avaliação da condição das árvores é uma valiosa ferramenta, que muito pode auxiliar no momento de tomadas de decisões com base nos resultados do inventário. Depois de concluído e analisado o inventário, a prefeitura deve definir um Plano Diretor de Arborização de Vias Públicas, para correta orientação técnica e administrativa. 


\section{REFERÊNCIAS BIBLIOGRÁFICAS}

ARAUJO, A. J. Método para avaliar a condição de árvores urbanas. In: Encontro Nacional sobre Arborização Urbana, 1997, Belo Horizonte - MG. Anais. Belo Horizonte, p.69,1997.

ARAUJO, A. J.; ARAUJO, M. N. Avaliação da Condição de Árvores Urbanas: Teoria e Prática. In: VIII Semana de Estudos Florestais, 2006, Irati - Pr. Anais. Guarapuava: UNICENTRO, p.166-172, 2002.

AUKEMA, J. E. Vectors, viscin, and Viscaceae: mistletoes as parasites, mutualists and resources. Frontiers in Ecology and the Environment, Washington, DC, v.1, n.3, p.212 219, 2003.

BIONDI. D; ALTHAUS, M. Árvores Urbanas de Curitiba - Cultivo e manejo. 1. ed. Curitiba: FUPEF, 2005. 117p.

BIONDI, D; REISSMANN, C. B. Avaliação do vigor das árvores urbanas através de parâmetros quantitativos. Scientia Forestalis. Piracicaba, n.52, p. 17-29, dez. 1997.

CARTILHA DA ARBORIZAÇÃO URBANA. Cidade das Árvores. Porto Alegre, Prefeitura Municipal, 2002. v.1.

COLTRO, M. E; MIRANDA, G. M. Levantamento da arborização urbana pública de Irati - PR e sua influência na qualidade de vida de seus habitantes. Revista Eletrônica Latu Sensu. v.2, n.1, jul.2007. Disponível em: <http://web03.unicentro.br/especializacao/ revista/edicao2/engenharias/ EN_LevArbo.pdf>. Acesso em: 02 set. 2008.

GONÇALVES, W; et al. Análise de árvores urbanas para fins de supressão. Revista da Sociedade Brasileira de Arborização Urbana. Piracicaba, v.2, n.4, p. 1-19, dez. 2007.

HARRIS, R. W. Arboriculture: integrated management of landscape trees, shrubs and vines. New Jersey: Prentice-Hall, 1992. 674p.

LOBODA, R. C. et al. Avaliação das áreas verdes em espaços públicos no município de Guarapuava/PR. Revista Electrónica de Geografía y Ciencias Sociales. Barcelona, v.9, n.194, ago. 2005. Disponível em:< http://www.ub.es/geocrit/sn/sn-194-71.htm>. Acesso em: 02 set. 2005.

MILANO, M. S. Avaliação quali-quantitativa e manejo da arborização urbana de Maringá-PR. 1988. 120f. Tese (Doutorado em Engenharia Florestal) - Universidade Federal do Paraná, Curitiba, PR.

MILANO, M. S.; DALCIN, E. C. Arborização de vias públicas. Rio de Janeiro, RJ: Light, 2000. 226p.

NORTON, D. A.; CARPENTER, M. A. Mistletoes as parasites: host specificity and speciation. Trends in Ecology \& Evolution, Amsterdam, v.13, n.3, p.101-105, 1998.

PIVETTA, K. F. L; SILVA FILHO, D.F. Arborização Urbana. Disponível em: <http://www.slideshare.net/flavia.smarti/arborizao-urbana>. Acesso em: 07 set. 2008. 
MILLER, R. W. Urban Forestry: planning and managing urban greenspaces. Englowood Cliffs, New Jersey: Prentice-Hall, Inc., 1988. 404 p.

PREFEITURA MUNICIPAL DE IRATI. Clima. Disponível em: <http://www.irati.pr.gov.br/municipio/clima.asp>. Acesso em: 03 set. 2008.

PREFEITURA MUNICIPAL DE MANAUS. Arborização Urbana. Disponível em: <http://www.manaus.am.gov.br/noticias/arborizacao-urbana-6>. Acesso em: 22 set. 2008a.

PREFEITURA MUNICIPAL DE MANAUS. Como podar e cortar árvores na cidade de Manaus. Disponível em: <http://www2.manaus.am.gov.br/portal/secretarias/semma/formularios/cartilha_ requerente.pdf>. Acesso em: 07 set. 2008b.

ROTTA, E. Erva-de-passarinho (Loranthaceae) na arborização urbana: Passeio Público de Curitiba, um estudo de caso. 135f. Tese (Doutorado em Engenharia Florestal) - Setor de Ciências Agrárias, Universidade Federal do Paraná, Curitiba, 2001.

SANTOS, E. Avaliação Quali-quantitativa da arborização e comparação econômica entre a poda e a substituição da rede de distribuição de energia elétrica da Região Administrativa Centro-Sul de Belo Horizonte-MG. Viçosa, MG: UFV, 2001. 219 p. Tese (Doutorado em Ciência Florestal) - Universidade Federal de Viçosa, 2001.

SANTOS, N. R. Z; TEIXEIRA, I. F. Arborização de Vias Públicas: Ambiente x Vegetação. 1.ed. Santa Cruz do Sul: Instituto Souza Cruz, 2001.

SOUZA, M. A. de I.B. Curso sobre arborização urbana. Belo Horizonte: CEMIG/SBAU/ IEF/AMIFLOR, 1995. 33 p.

TAINTER, F. H. What does mistletoes have to do with Christmas? Feature Story. St. Paul: The American Phytopathological Society, 2002. Disponível em:

<http://www.apsnet.org/online/feature/mistletoes> Acesso em: 20 jul. 2005.

ZILIOTTO, M. A.; SEITZ, R. A.; MIELKE, E.; SALGUEIRO, R. L. Experiências práticas na condução do controle de ervas-de-passarinho de diferentes espécies na arborização de Curitiba (PR). In: ENCONTRO NACIONAL DE ARBORIZAÇÃO URBANA, 8., 1999, Fortaleza. Anais. Fortaleza: SBAU, p.76-78,1999. 